WTERFFAEF TECNOLOGGCA

\title{
A LOGÍSTICA E OS NÍVEIS DE SERVIÇOS NAS EMPRESAS
}

\section{LOGISTICS AND LEVELS OF SERVICES IN COMPANIES}

\author{
Rhuan Antonio Miqueluti - rhuanmiquelutii@gmail.com \\ Faculdade de Tecnologia de Taquaritinga - Taquaritinga - São Paulo - Brasil \\ Fábio Luís Sobral - fabio.sobral@fatec.sp.gov.br \\ Faculdade de Tecnologia de Taquaritinga - Taquaritinga - São Paulo - Brasil
}

DOI: 10.31510/infa.v18i1.1121

Data de submissão: 16/04/2021

Data do aceite: $09 / 07 / 2021$

Data da publicação: 30/07/2021

\begin{abstract}
RESUMO
A logística e os níveis de serviços, têm a finalidade de organizar os processos e agilizar o ganho de produtividade, qualidade e tempo. Então, este artigo, se trata de um estudo sobre a logística e os níveis de serviço da área, sendo o principal objetivo compreender que a logística é fundamental para qualquer empresa, uma vez que, se uma organização tiver produtos excelentes, porém não entregar no prazo estipulado pode interferir no feedback que o cliente irá transpassar sobre a empresa. As metodologias que compõem o presente artigo são de caráter bibliográfico e exploratório e através dessas técnicas de pesquisa pode-se constatar a importância dos níveis de serviço na logística e dos indicadores utilizados para avaliação nesse campo. Conclui-se então que a empresa que quer se manter ativa e a frente do mercado competitivo, necessita investir e consequentemente melhorar os níveis logísticos da organização.
\end{abstract}

Palavras-chave: Logística. Níveis de serviço. Indicadores de desempenho. Feedback. Clientes.

\begin{abstract}
Logistics and service levels are designed to organize processes and speed up productivity, quality and time. So, this paper is a study on logistics and service levels in the area. The main objective is to understand that logistics is fundamental for any company, since if an organization has excellent products, but does not deliver on Overtime can interfere with the feedback that the customer will pass on the company. The methodologies that make up this article are bibliographic, descriptive and exploratory and through these research techniques can be seen the importance of service levels in logistics and the indicators used to evaluate them. It is concluded that the company that wants to stay active and ahead of the competitive market, needs to invest and consequently improve the logistic levels of the organization.
\end{abstract}

Keywords: Logistics. Levels of service. Performance indicators. Feedback Customers. 


\section{[NTERFFAET TECNOLOGGCA}

\section{INTRODUÇÃO}

Segundo Araújo (2010), "suprir e vender os produtos, é o que sustenta uma organização, porém, não é viável que através da má distribuição esses dois fatores sejam atingidos." $\mathrm{O}$ autor afirma que, a logística é pouco valorizada diante da importância que ela tem para os clientes e do diferencial que ela pode significar, quando aplicada corretamente de acordo com o nível de serviço de cada organização.

Nesse contexto, pode-se notar que entregar os produtos, no prazo e local combinados com os clientes, tem se tornado obrigação das empresas. Araújo (2010) diz que "os maiores desafios atualmente, é tornar a saída do produto mais eficiente, eficaz e com um custo interessante para a empresa e para o consumidor."

Bowersox e Closs (2010), afirmam que "o objetivo primordial da logística, é alcançar o nível de excelência para o cliente, procurando reduzir os custos em uma maior escala, além de oferecer alternativas que contribuam para a satisfação do mesmo."

Segundo Santos (2006), "o nível de serviço é a mensuração que irá indicar o nível de qualidade e conforto entregue ao consumidor." A partir desta afirmação, compreende-se que os níveis de serviços são necessários na logística, uma vez que nos permite através dos indicadores, calcular se as metas estabelecidas estão sendo cumpridas.

Então, é explicito a necessidade de determinar, quais serão os indicadores que irão medir o nível de serviço da empresa, bem como também identificar as expectativas e necessidades do cliente perante a organização, o produto e o serviço prestado (SILVA; BRAND, 2010).

Bertaglia (2003), "afirma que as empresas de sucesso, necessitam reconhecer e buscar uma melhoria contínua e visão sistêmica, a partir de informações também do ambiente externo, para que atendam as necessidades da cadeia de abastecimento."

Portanto, o presente artigo, baseia-se no estudo da logística e dos níveis de serviço nas empresas, com o intuito de demonstrar a importância do assunto nas organizações. Sendo o principal objetivo, realizar uma pesquisa bibliográfica para fins de estudos mais aprofundados e melhor compreensão do tema.

Fleury et al. (2007), afirma que "o atendimento ao cliente é o diferencial para a logística tradicional, uma vez que a procura não está somente na eficiência e qualidade do produto, mas, também está ligada ao atendimento das exigências do consumidor no produto ou serviço prestado." 


\section{[NTERFFAET TECNOLOGGCA}

\subsection{Objetivos}

O objetivo deste artigo é estudar a logística e os níveis de serviços que envolvem essa área, o estudo será realizado através de pesquisas bibliográficas, para que haja um contato com acadêmicos ou empresários, que entendem ou já tenham contato com essa área, evidenciando também os indicadores utilizados em algumas organizações e que cooperam para elaboração de demonstrativos de resultados, sobre a eficiência da empresa, em relação ao nível logístico que ela atende.

\subsection{Justificativa}

A relevância do estudo, advêm da necessidade de tratar a logística como um dos fatores mais importantes no sucesso de uma organização, bem como da necessidade de entender os diferentes níveis de serviço nas pequenas e médias empresas.

\section{A IMPORTÂNCIA DA LOGÍSTICA NAS ORGANIZAÇÕES.}

Segundo Neto e Santana (2015), "no passado a logística estendia-se apenas ao transporte de produtos alimentícios e ao abastecimento de munição aos soldados no campo de batalha." Os autores dizem que atualmente a logística representa o controle nos processos, desde a entrada de matérias primas, até a saída dos produtos e a entrega dos mesmos ao consumidor.

Bowersox e Closs (2007), afirmam que "a logística é uma área de atuação, que abrange toda a administração interna de um ambiente empresarial, movimentando produtos, informações e serviços em todo processo."

Para melhor compreender a importância da logística nas organizações, se faz necessário, entender o conceito desta área, sua dimensão no Brasil e as estratégias dessa área de atuação no mercado competitivo.

\subsection{Conceito de logística}

Segundo Martins et al. (2006), “a logística é responsável pelo controle e processo dos fluxos de mercadorias, produtos e informações, desde os fornecedores até os consumidores." 


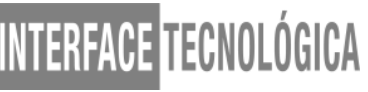

Neto e Santana (2015), afirmam que "a logística é conhecida pela distribuição física, que fornece e gerencia processos dentro de uma organização". Então, é possível notar que essa área passa a atingir outros pontos além do transporte e começa a integrar toda a organização.

A logística pode também ser compreendida, como a junção de quatro atividades, sendo elas aquisição, movimentação, estoque e entrega do produto ao consumidor, sendo necessário um planejamento logístico, que torne essas atividades funcionais e possibilitando assim uma interação entre elas (BALLOU, 2009).

Então, nesse contexto a logística é a integração de várias atividades, a fim de satisfazer as necessidades de qualidade, agilidade, preço e atendimento do consumidor. Bowersox $\underline{(2010)}$ entende a "logística como uma maneira de satisfazer o cliente, uma vez que as integrações que a compõe, está voltada as necessidades do mesmo.”

De acordo com Neto e Santana (2015), “a logística ganha uma definição mais moderna, pois a logística hoje, tem como principal conceito maximizar os lucros das empresas através de um atendimento mais ágil e eficiente com seus clientes.”

\subsection{Dimensão da logística no Brasil}

Martins et al. (2006), acredita que a logística, seja dividida em três dimensões, sendo elas de fluxo, processo e domínio, bem como a primeira dimensão caracterizada pelo conceito inicial de suprimentos, transformação, distribuição e serviço ao consumidor, a segunda ligada ao planejamento estratégico administrativo, baseado na logística como ferramenta e a terceira caracterizada pela tomada de decisões através da logística como estatística.

Nesse contexto é possível analisar, que a logística em suas três dimensões, engloba toda a empresa, ou seja, ela é capaz de controlar, e determinar processos nas organizações, a fim de trazer melhorias de forma holística.

Segundo Ribeiro e Carvalho (2010), "no Brasil na década de 90 e após a mobilização empresarial, a logística passa por um processo revolucionário, seja no gerenciamento, eficiência, qualidade ou na disponibilidade de infraestrutura de transporte e comunicação."

Ribeiro e Carvalho (2010), descrevem os seguintes fatores que impulsionaram a logística no Brasil:

- Abertura do comércio internacional;

- Troca de tecnologias;

- Estabilidade econômica com o plano real; 


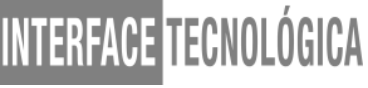

- Certa equidade de produção com alguns países desenvolvidos;

- Privatização de infraestrutura, das rodovias, ferrovias e portos.

A logística no Brasil conta atualmente, com transportes rodoviários em sua maior parte, ferroviários para grandes distância e menor custo, hidrovias para cargas volumosas, pesadas e descarregamento mecânico e o transporte aéreo utilizado apenas para pequenas cargas (RIBEIRO; CARVALHO, 2010).

\subsection{Estratégias da logística no mercado competitivo}

É um fato, que o cliente é a peça fundamental para o sucesso de um negócio, assim como a sua satisfação perante os produtos e serviços da empresa. As organizações tendem a olhar a logística como forma de fidelização dos consumidores, através da agilidade e credibilidade dos produtos e serviços prestados, conquistando assim o principal, os lucros da organização. O que torna necessário o uso de uma gestão logística competente, capaz de planejar, gerenciar, controlar e dirigir esforços tecnológicos em prol da empresa.

Novaes (2007), acredita que "a logística pode ser estimulante, através da enorme quantidade de tarefas que essas áreas citadas podem trazer, tornando o gerenciamento estratégico de logística desafiador, estimulando a empresa em um só propósito."

É fato que uma boa gestão logística, traz vantagens competitivas para a organização, porém, é necessário destacar, que uma das obrigações da equipe de gestão é tomar decisões corretas mediantes os problemas. Kotler (2006) afirma que "há quatro decisões corretas e necessárias a se fazer, em relação a escolha de estratégias para a organização, sendo elas, processamento de pedidos, armazenagem de estoque, estocagem e como esses produtos serão distribuídos."

O autor afirma que "para cada decisão a ser tomada, uma estratégia diferente deve ser adotada, entretanto, todas as estratégias farão parte do planejamento estratégico da cadeia de abastecimento da organização, possibilitando a obtenção do lucro esperado e a sobrevivência no mercado competitivo" (KOTLER, 2006).

Kotler (2006), aponta algumas estratégias que podem ser utilizadas, são elas:

- Liderança nos custos: para as empresas que desejam diminuir custos desde a matéria prima, até o consumidor. Contém o perfeito controle do fluxo e reduz o número de fornecedores.; 


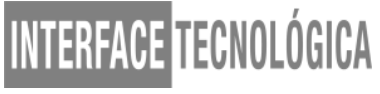

- Diferenciação: foco na qualidade do serviço logístico da empresa, possui vantagens quando se trata de produtos mais delicados de trabalho;

- Inovação: é o marketing, relaciona o fluxo físico, com o TI e a automação do centro de distribuição da empresa;

- Parceria: relacionado às alianças conquistadas, com novas empresas ou transportadoras que atende a todas as solicitações;

- Expansão: utiliza a logística como forma de obtenção de mais clientes e ampliar a missão da empresa;

- Diversificação: permite aos clientes a escolha na forma de compra e recebimento dos produtos ou serviços.

Então, diante dessas estratégias mencionadas acima, é possível compreender também a relevância que a essa área de estudo tem sobre a lucratividade e o sucesso de uma empresa, além de suas estratégias serem flexíveis de acordo com os problemas encontrados e decisões tomadas.

\section{PROCEDIMENTOS METODOLÓGICOS}

A presente pesquisa é de caráter bibliográfica e exploratória, a fim de evidenciar uma área de estudo muito importante mundialmente, uma vez que todas as empresas, organizações, comércios varejistas e até mesmo os governos necessitam da logística como meio de controle de processos e ferramenta de lucratividade.

Então, foi traçado um planejamento a fim de estudar a importância da logística e dos níveis de serviços ao cliente nessas organizações, bem como os conceitos e as fases pelo qual o nível de serviço percorre.

Segundo Marconi e Lakatos (2010), "a pesquisa bibliográfica abrange toda bibliografia, mídia ou documentos já publicados em torno de um assunto." Os autores também afirmam que a pesquisa descritiva e exploratória, são investigações e estudos, para compreender o tema de estudo (MARCONI; LAKATOS, 2011). 


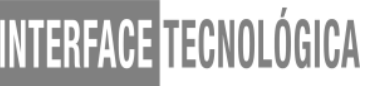

\section{RESULTADOS E DISCUSSÃO}

\subsection{Nível de serviço}

Ballou (1993), “em seu ponto de vista, descreve o nível de serviço logístico, como o resultado da qualidade, participação e planejamento de uma empresa nos produtos e serviços prestados aos seus consumidores.” Então, a logística é a métrica da eficiência, da satisfação e fidelização dos clientes na organização.

Christopher (2007), afirma que “a vários tópicos que compõe o nível de serviço em uma empresa, sendo eles:

- Todas as atividades devem ser acompanhadas desde a captação, entrega e faturamento de pedidos, a fim de que não haja falhas;

- Pontualidade e credibilidade na entrega dos produtos, de acordo as expectativas dos clientes;

- Todas as áreas do negócio devem estar envolvidas em um só propósito, a fim de que seja perceptível a missão e os valores da organização;

- Controle total de todas as entradas e saídas, da comunicação com o cliente, das remessas e fretes, das faturas e controle também dos reparos a serem realizados nos produtos;"

O nível de serviço é relacionado diretamente à relação de empresa e cliente. Faria e Costa (2008) “interpretam o nível de serviço como um processo integral da relação e atendimento do pedido do consumidor."

Contudo, os autores Faria e Costa (2008) 'afirmam que o nível de serviço logístico é a capacidade da organização, em gerar valor ao produto ou serviço prestado, com o intuito de atender e superar as expectativas do consumidor perante a empresa."

Lei, He e Nie (2013), afirmam que "o nível de serviço logístico tem a capacidade de influenciar no market share e rentabilidade de uma empresa, estando também relacionado ao preço pago pelas organizações na logística de transportes, armazenagem e sistemas da informação, a fim de que todas as necessidades do cliente sejam atendidas."

Por esse motivo é fácil compreender que, o serviço ao cliente não está ligado somente à qualidade e preço do produto, mas, também está relacionado aos fatores citados acima, a disponibilidade da empresa e de seus produtos, sendo também de extrema importância o bom atendimento. O autor Fleury et al. (2007), "afirma que além de todos esses esforços a logística tem o objetivo principal reduzir custos e trazer vantagem competitiva a organização.” 


\subsection{Elementos do serviço}

Kotler (2006), “classifica, menciona 4 P's e divide em grandes grupos, o que são conhecidas como ferramentas de marketing, para compor os elementos de serviço ao cliente, que são elas:

- Produto: ligado a todas as características física, de designer, valor agregado e preço do produto;

- Preço: relacionado aos prazos, condições de pagamento etc.;

- Promoção: foco na publicidade e marketing dos produtos ou serviços prestados;

- Praça: variedade de produto, estoque, transporte."

O nível de serviço ao cliente é um componente fundamental, tanto para o planejamento estratégico de marketing, quanto para o principal objetivo das empresas, que é gerar lucro ao gerir e atender o maior número de demandas.

Ballou (2006) acredita que o nível de serviço é um mix dos 4P's de marketing, tornando possível, a identificação dos elementos que compõe o serviço logístico de uma empresa. A identificação desses elementos surge de uma operação do fornecedor com o cliente, o autor separou esses elementos em 3 categorias, que são avaliadas de forma conjunta, uma vez que o cliente avalia e explana sua opinião sobre todo o processo.

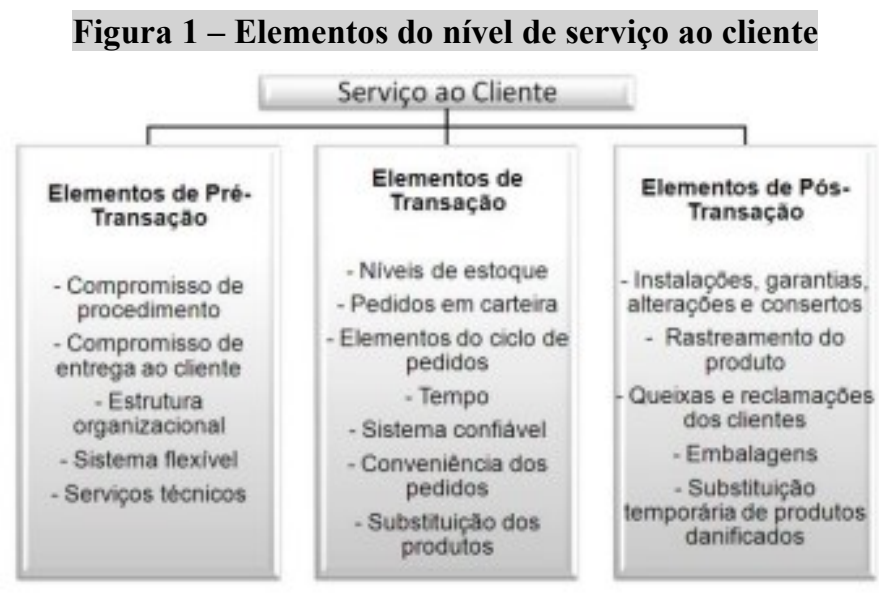

Fonte: Ballou (2006).

Na figura 1, Ballou (2006) “define o elemento de pré-transação como o responsável pela criação do ambiente e elabora um plano de trabalho, o de transação ocorre durante a venda e 


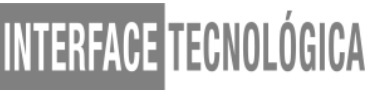

está relacionado diretamente à entrega do produto, e a pós-transação relacionado ao planejamento pós-venda, associado a instalação, garantia e assistência técnica."

\subsection{Indicadores de nível de serviço}

Miranda (2001) "os indicadores são criados para fins de mensuração da eficiência e eficácia dos procedimentos logísticos da empresa, diante do ponto de vista de seus consumidores, desde a captação dos pedidos, até o feedback dos seus clientes sobre a satisfação deles quanto ao trabalho da empresa."

De acordo com Bowersox e Closs (2007), classificam vários indicadores como fundamentais para gerir resultados sobre os trabalhos da organização, esses indicadores estão divididos em 4 grupos, que são os grupos_ primeiro: captação e fornecimento de produtos; segundo: capacidade de lidar com falhas; Terceiro: medidas de qualidade, transporte e suporte pós-venda; e o quarto: que são as medidas genéricas que variam de empresa a empresa.

A seguir, na figura 2, é possível visualizar alguns indicadores comuns em muitas empresas, bem como a porcentagem de clientes que respondem a esses indicadores e a relevância de cada indicador do ponto de vista do consumidor.

Figura 2 - Indicadores comuns nas organizações

\begin{tabular}{|c|c|c|}
\hline INDICADOR & $\begin{array}{c}\text { \% DE CLIENTES QUE USAM O } \\
\text { INDICADOR }\end{array}$ & \begin{tabular}{|} 
\% DE CLIENTES QUE O \\
RECONHECEM COMO MUITO \\
IMPORTANTE
\end{tabular} \\
\hline Entregas $100 \%$ no prazo & 86 & 91 \\
\hline $\begin{array}{l}\text { Preenchimento } 100 \% \text { nas ordens de } \\
\text { venda }\end{array}$ & 75 & 88 \\
\hline $\begin{array}{l}\text { Acuracidade das Faturas (faturas } \\
\text { sem erros) }\end{array}$ & 69 & 77 \\
\hline $\begin{array}{l}\text { Performance no cumprimento dos } \\
\text { prazos de entrega }\end{array}$ & 66 & 82 \\
\hline $\begin{array}{l}\text { Tempo de atendimento da ordem de } \\
\text { venda }\end{array}$ & 63 & 78 \\
\hline $\begin{array}{c}\text { Excessos de Estoque / Pedidos } \\
\text { pendentes (falta de estoque) }\end{array}$ & 62 & 84 \\
\hline $\begin{array}{l}\text { Quantidades entregues a mais ou a } \\
\text { menos / Danos nas entregas }\end{array}$ & 61 & 73 \\
\hline $\begin{array}{l}\text { Itens de ordens de venda } 100 \% \\
\text { atendidos }\end{array}$ & 55 & 84 \\
\hline Devoluções e Reentregas & 44 & 63 \\
\hline Custo de Frete & 44 & 68 \\
\hline Tempo de resposta a consulta & 36 & 63 \\
\hline $\begin{array}{c}\text { Preenchimento de caixas } \\
\text { embalagens }\end{array}$ & 32 & 77 \\
\hline
\end{tabular}

Fonte: Elaborado por Bowersox e Closs (2007) 


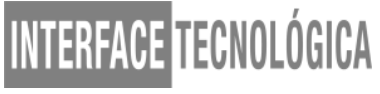

A partir dos estudos bibliográficos, foi possível compreender a relevância do tema de estudo dentro das organizações, uma vez que a logística, o nível de serviço nas empresas e os indicadores, são ferramentas eficientes e eficazes para a empresa, a fim de que a mesma consiga destacar os pontos positivos e negativos com mais facilidade, resolver problemas e atender as necessidades de seus clientes, com o objetivo de conseguir a satisfação do consumidor, a fidelização do mesmo e consequentemente uma maior lucratividade para seu ramo de negócio.

\section{CONCLUSÃO}

A partir dos dados e elementos identificados através do estudo, é possível concluir que a logística e os níveis de serviço, é um tema que merece destaque nas organizações, não só no Brasil mais no mundo, em especial nas indústrias grandemente reconhecidas por suas marcas e produtos.

Muitas vezes a falta e deficiência de indicadores, podem contribuir para defasagem ou inexistência dos feedbacks dos clientes de uma organização. Dificultando e inviabilizando melhorias e tomadas de decisões por parte das empresas, uma vez que se a organização não sabe a opinião dos seus clientes sobre a logística utilizada, a mesma não pode atuar com possíveis melhorias.

É fato que a logística é indispensável em qualquer organização, pois essa área tem a função de delegar funções e procedimento, além de planejar, organizar, controlar e dirigir esforços para que a empresa tenha um fluxo contínuo e atenda as necessidades de seus consumidores. Então, a partir dessa perspectiva surge uma preocupação, de como coordenar a logística para que ela seja efetiva e contribua para o bom andamento da empresa.

E por fim, pode-se concluir que é imprescindível que as empresas invistam em indicadores eficientes, para obtenção de resultados e assim conseguir efetuar as devidas melhorias nos processos logísticos e no nível de serviço já existente na organização.

\section{REFERÊNCIAS}

ARAÚJO, W. A logística de distribuição em pequenas e médias empresas. CAFÉ COM ADM, [S. 1.], 21 ago. 2010. Disponível em: <https://administradores.com.br/artigos/a-logistica-dedistribuicao-em-pequenas-e-medias-empresas $>$. Acesso em: 20 set. 2019.

BALLOU, R. H. Gerenciamento da cadeia de suprimentos/logística empresarial. 5. ed. Porto Alegre: Bookman, 2006. 
BALLOU, R. H. Logística Empresarial: transportes, administração de materiais e distribuição física. 2. ed. São Paulo: Atlas, 2009.

BALLOU, R.H. Logística Empresarial: transportes, administração de materiais e distribuição física. Tradução Hugo T. Yoshizaki. - São Paulo: Atlas, 1993.

BERTAGLIA, P. R. Logística e gerenciamento da cadeia de suprimentos. São Paulo: Saraiva, 2003.

BOWERSOX, D. J.; CLOSS, D. J. Logística empresarial: o processo de integração da cadeia de suprimento. São Paulo: Atlas, 2010.

BOWERSOX, D. J; CLOSS, D. J. Logística Empresarial: o processo de integração da cadeia de suprimentos. São Paulo: Atlas, 2007.

CHRISTOPHER, M. Logística e gerenciamento da cadeia de suprimentos. $2^{\mathrm{a}}$ Edição. São Paulo: Pioneira, 2007.

FARIA, A. C.; COSTA, M. F. G. Gestão de custos logísticos: custeio baseado em atividades $(\mathrm{ABC})$, balanced scorecard (BSC), valor econômico agregado (EVA). São Paulo: Atlas, 2008.

FLEURY, P.F. et all. Logística empresarial: a perspectiva brasileira. São Paulo, Atlas: 2007.

KOTLER, P. Administração de marketing. São Paulo: Atlas, 2006.

LEI, W.; HE, X; NIE, K. Pricing decision research for TPL considering different logistics service level influencing the market demand. Journal of Industrial Engineering and Management, 2013. Disponível em: <http://www.jiem.org/index.php/jiem/article/view/662/384>. Acesso em: 15 de set. 2019.

MARCONI, M. DE A.; LAKATOS, E. M. Técnicas de pesquisa. 7. ed. São Paulo: Atlas, 2010.

MARTINS, P. G. et al. Administração de Materiais e Recurso Patrimoniais. 3 ed. rev. e atualizada. São Paulo: Saraiva 2006.

MIRANDA, R. C.. Inteligência Organizacional e Competitiva. R. Balanced Scorecard. Traduzido por TARAPANOFF, K. (Org.) Brasília: Editora Universidade de Brasília, 2001.

NETO, U. J. S.; SANTANA, L. C. Logistica e serviço ao cliente como estratégia competitiva. 2015. Monografia (Ensino Superior) - Fundação Viscondi Cairu, 2015. Disponível em: $<$ https://www.cairu.br/riccairu/pdf/artigos/2/07_LOGISTICA_SERVICO_CLIENTE_.pdf $>$. Acesso em: 22 set. 2019.

NOVAES, A. G. Logística e Gerenciamento da Cadeia de Distribuição: estratégia, operação e avaliação. Rio de Janeiro: Campus. 2007. 
RIBEIRO, Alessandro Aurélio; CARVALHO, Alessandro Carvalho. A importancia da logística das empresas. 2010. Monografia (Superior em Administração) - Faculdade integrada do Vale do Ivaí, $[S . \quad l],. \quad 2010$. Disponível em: $<$ http://www.univale.com.br/portalnovo/images/root/anaisadmix/2.pdf $>$. Acesso em: 19 set. 2019.

SANTOS, L. M. Risco de Sobrevivência de Micro e Pequenas Empresas Comerciais. Ribeirão Preto: RCO, 2006.

SILVA, R. M.; BRAND, G. Aplicando o processo de pensamento da TOC (teoria das restrições) através da árvore da realidade atual (ARA) para extratificar o problema de desorganização em um centro de distribuição. INGEPRO, [S. 1.], 2010. Disponível em: $<$ http://www.ingepro.com.br/index.php/ingepro/viewFile/107/98 >. Acesso em: 23 set. 2019 